\title{
The region in the boot: mobilising lone subjects and multiple objects
}

\section{Eric Laurier, Chris Philo}

Department of Geography and Topographic Science, University of Glasgow, Glasgow G12 8QQ, Scotland; e-mail: elaurier@geog.gla.ac.uk,cphilo@geog.gla.ac.uk

Received 26 June 2001; in revised form 5 July 2002

\begin{abstract}
Company regions are forms of space busy with the sorting and distributing of objects from one location to another. We argue here, in sympathy with actor-network theory and nonrepresentational theory, that space is formulated by and formulative of its objects in mutually elaborating occasions and chains of action. The handling of objects that produces regions requires not simply that they are put in a place, but that they are put in a relevant place. Finding the relevant where is bound to the relevant when in the sense that the uses of objects are bound to sequential considerations of the kind: what happens next? Regions are cultural, social, political, and sometimes theoretical entities for economists, geographers, and other professional social scientists, but they are also topics of concern to regional managers of business companies, who are unavoidably and pervasively involved in the practical activities of spatial organisation. In this paper we are pursuing the situated replication of sociospatial technologies, or, in other words, how the same thing is done over and over again by local employees, with both the materials that they have at hand and the contingent circumstances in which they locate themselves. In pursuing our analysis we follow one particular mobile worker as she goes about her daily work of managing her region. What we attempt to excavate from our ethnographic material is the order that is endogenous to those activities. It is an everyday order that does not turn on spectacular technologies but turns, rather, on mundane ones such as stacking cardboard boxes, arranging items in the boot of a car, and driving around a city.
\end{abstract}

\section{Introduction: issues and methods}

\section{Locating the company in its geography}

The sales region may appear as a map you see pinned to the wall if you visit a transnational company at its headquarters to do an interview with one of its managers: a map of key locations where this company's operations are conducted or to which they are directed, perhaps with thick lines drawn to mark its edges and subdivisions. With some delight you think: 'Aha! A representation of the company region. Just what I was looking for'. When no one is looking you scan the map for clues, for signs that could be decoded, parts of a hidden ideological construction of space. Then, after hanging around at headquarters for a while, you notice that the members of the company largely ignore the map. They talk a lot about various places, which you realise have pins stuck in them, although often they do not even mention the names on the map but, rather, refer to the names of the people from these places. They talk about personalities, they talk about promotions, they talk about turnover, and they talk about where the company's products go. You found the company easy enough at headquarters, but where, you wonder, is the geography of its region to be found if not on the map?

In a tactical manoeuvre familiar to cultural geographers, critical theorists, and sociologists of scientific knowledge, we want to move away from elaborate readings of the map, away from the boardroom overview, down to the ground-level organisational labour required to make the company region happen. We want to shift out of the central office to observe some of the work as it is done by those whose daily business it is to manage a company's region or regions. This shift to find out what happens outside of headquarters is not just about looking for 'where the action is' (Goffman, 1969), it also follows a shift in the practices of other service-sector workers (Laurier and Philo, 1998), 
who increasingly suggest that their companies are ever more urgently pushing managers out of their central offices and into their regions. ${ }^{(1)}$ Company policy from one transnational corporation (TNC) recommends that in the average five-day week as many as three days should be spent visiting clients on site. Regional managers who spend all day at their desks are criticised for losing touch with their clients. In the case study reported on here the company had removed traditional office facilities for its regional managers entirely and expected them to use their cars as offices.

In what follows we will focus upon a workplace where the traditional central office environment has been emptied out and merged into the work sites of its dispersed customers. Or, to put it another way, some of the workers from the office have been sent out in their company cars with newly available mobile technologies (mainly telephones but also portable computers) to do more on-site service work with their clients. At this point we do not wish to speculate on the implications of these workers becoming more mobile, we wish instead to examine elements of what this form of spatially dispersed labour entails:

"Life at work is a staple in our conversations, but we rarely talk about what we really do in the doing of a job. This omission extends to the professional literature on work: most such literature is not concerned with work as practice, by which I mean that these writings do not focus on what is actually done in accomplishing a given job. Instead, most are centred on work as the relation of employment or on work as a source of the worker's identity. Although such writings are inevitably based on assumptions about practice, practice itself is usually taken for granted, and the basis of the assumption remains implicit" (Orr, 1996, page 1).

Our investigation is akin to a 'shop-floor' description of work practices, except that for mobile workplaces there is no 'shop floor'. Nevertheless, their work practices remain reflexively tied to spaces, and for the kind of workers with whom we are concerned here work practices are tied to the spaces of their regions. Moreover, the activities here are the 'behind the scenes' aspects of service work, unseen by clients, yet without which sales performances (inasmuch as they are at all theatrical) could not be done.

We will follow only one mobile worker, but what our study lacks in extensivity it makes up for in the intensivity of bringing into view the myriad practical aspects of making regions. To extend our findings would involve further ethnographies of regional work of the kind we are doing here, not only for similar kinds of companies but also for other workers who have to do their work across regional spaces. By describing the practical activities of producing a sales region, we hope to show the lack of inevitability in the production of regions as spatial forms, underlining that they are likely to be quite precarious material accomplishments, locally established pockets of order in the changing arrangements of each and every company (see also Thrift, 1996). Furthermore, in line with arguments about regarding institutions as ongoing, mutable, and indeed reversible achievements (Philo and Parr, 2000), we suppose that the company region is itself an achieved spatial order needing constant attention, repair, and heterogeneous labours. ${ }^{(2)}$ A company region, once of interest to an older version of industrial

(1) The need to be out on the road visiting clients, dispersed colleagues, and customers has been a lifelong element of many jobs, but our fieldwork suggested that it is becoming a more important aspect of jobs not previously characterised by such a mobile existence. This view from our participants is supported by statistics gathered by the ESRC (Economic and Social Research Council) Transport Studies Unit (Goodwin et al, 1995), who suggest that the percentage of journeys that are work-related has grown to a figure of $70 \%$; thus they are now by far the commonest type of car trip.

(2) Following Crang (2000), amongst others (Du Gay, 1996), we are widening the senses of labour to include not just physical activity but also emotional, dramaturgical, conversational, technological, and other activities; and relatedly, with Crang, we agree that there are then different forms of 'surplus value' to be extracted from each kind of action. 
geography, is clearly a quite specific form of region-an artificial and constructed one-but we are proposing that our ethnographic descriptions of 'managing' a company region can inform broader debates about geographical regions less as pregiven 'natural' entities and more as fabricated 'social' entities (Allen et al, 1998; Thrift, 1994).

\section{Of transporting objects}

We are in no doubt that the mobility of people and materials is centrally implicated in making company regions. This claim is hardly an exceptional one, but we hope that how we elaborate its implications may have some novelty, and it has underlain our joint research on the lives, experiences, and practices of car-based mobile workers, a corner of which we will present here. ${ }^{(3)}$ Our car-based mobile workers, mostly individuals who 'go out into the field'(4) to promote products and/or to offer services to established or potential clients, can be envisaged as occupying places in motion during working hours. Their cars are their places, and they function as office, storage, and delivery vehicles, repeatedly criss-crossing a defined, if changing, territory of operations. Mobile workers spend hours in transport systems, sitting on trains, buses, tubes, driving, and walking. Only occasionally do they come to rest at meetings with clients in the clients' workplaces (their offices, premises, workshops) or with fellow workers at agreed rendezvous points (a motorway service station, a known restaurant, coffee shop, café, or bar). ${ }^{(5)}$ A few of these mobile workers are in business for themselves, but most of them are employees of larger companies with fixed headquarters. The immediate and simple counterfactual is that were the mobile workers not regularly and routinely 'out there in the field', moving and meeting, there would eventually be no company region: the region would cease being maintained and reproduced on a daily basis, and the map on the boardroom wall would gradually become a historical artefact with little associative power beyond its two-dimensional lines, blobs, and spaces (Law and Hetherington, 1999). Clients would be stolen by other TNCs, and headquarters would have a weaker and weaker awareness of what is happening outside its walls.

The mobile workers do not move across their regions in the form of, as it were, 'naked subjects'. They travel with a complex assembly of equipment, some of it high tech and much of it not. Their 'product' is not a 'naked object' either, and appears as a complex topical assembly of packaging, documentation, advertising, contracts, and so on. The practical problem faced by mobile workers is how much of their equipment can they transport and how can they get the 'product' to the clients' distant places? Hindmarsh and Heath, in their paper on a restoration control office for a telecoms network, put the tie between objects and workplaces very nicely, as they study:

"how personnel within a complex working environment refer to and examine objects and, through their interaction, constitute the occasioned sense and relevance of particular features of those objects within the course of their workplace activities. In this way, we use the term objects very loosely, as a way of glossing a diverse range of (features of) tools; technologies and materials; paper documents such as

(3) See also: on talk, Laurier (2001a); on travel, Laurier (2001b); and on driving, Laurier (2001c).

(4) The resonance between their knowledge of 'the field', even of 'the region', and that of most academic geographers is intriguing; it would probably warrant further comment, which we provide to a limited extent below.

(5) Our mobile workers were at different levels in company hierarchies, with some participants in our project, like a human-resources officer ('Penny', in Laurier and Philo, 1998), being quite senior (having her own nonmobile office and secretarial support) but with others, like Marge, being much more junior. For other work on contemporary nomadic workers and new technologies, see the computer-supported cooperative work collections Brown et al (2001) and Dix and Beale (1996). For a history of traveling salespeople which shows the long lineage of the car-based worker, see the delightful Spears (1995). 
logbooks and manuals; digital displays of text; diagrams and images; and artifacts such as pens, keyboards, telephones and the like" (2000, page 527).

Akin to Hindmarsh and Heath, we are pursuing not 'objects' per se, but rather the relevance of particular varieties of objects as they are implicated in practices that are sometimes about representing but are as often involved in a richer weave of packing, loading, dropping off, picking up, and marking (as in marking 'for the attention of', and very often in announcing the impending or current work of managing a sales region: see also Kawatoko, 1999). This point about the 'spatial announcement' of objects within such practices will be elaborated in our later description and analysis.

The shift by Latour, Thrift, and others toward taking 'the agency of things' seriously has raised questions about the extent and form of social agency that might be attributed to specific kinds of nonhumans (Laurier and Philo, 1999). In other work we have teased out aspects of the lifeworld of animals in cities and in society more generally (Laurier et al, 2002; Philo and Wilbert, 2000). Though we have taken inspiration from Latour's widened sense of the social constituency as including all manner of things, from engineers, via seatbelts as nonmaterial couplings, to domestic cats, we are wary about making too easy an equivalence between humans and nonhumans or indeed between the very many kinds of nonhumans. The social agency which we can find for each and every thing requires not only its close description as a historical entity, living, dead, or inanimate, but also attention to which of its aspects are made relevant on any occasion of its use.

In this paper we are wanting to take objects seriously in how they are implicated, and even assist, in forms of social action. Moreover, we are suspending what we might call the distracting glitter of certain kinds of objects-say, diamonds or space shuttles - to allows us to build criteria which do not exploit the pregiven value of the objects in question. In so doing, all manner of quite humble and mundane objects swim into focus; there are exemplary studies inspiring us in this respect, such as Latour's (1992) description of a self-closing hinge, Polanyi's (1958) study of a blind person's walking stick, even Foucault's (1987) remarkable excavation, inspired by Raymond Roussel, of the "small objects ... taking on the appearance of flashing beacons" (page 102) within the "infinitely chatty landscapes" (page 115) so lovingly detailed by Roussel. One commonality in these contemplations on the place of objects in human activity is to register that they are historically fashioned tools or equipment always tied to complexes of technology and practice. In what follows we will investigate elements of a mobile worker's day that involve handling, moving, and orienting to such 'grey' and apparently uninteresting items as cardboard boxes, plastic bags, and shrinkwrapped bottles. We are specifically examining the reflexive tie between such objects as they get used in organising space and the spatial arrangement of these objects themselves, the latter of which is integral to how situated agents makes sense of said objects. All of this endeavour on our part will display how the practices of mobile workers, when transporting, packing, and unpacking the likes of boxes, bags, and bottles, encapsulates a suite of previously hidden but arguably indispensable region-building practices.

\section{Brief remarks on our practice as researchers}

In keeping with policies of ethnomethodological studies, we have been committed to explicating the methods by which competent members get things done (where 'member' can stand for any agent categorically tied to activities). Ethnomethodological studies are distinct from most social and cultural approaches by virtue of not proposing that the formalised methodologies of the social sciences be administered upon research settings to deliver results. Instead, the methods and methodologies of the 
social sciences are taken as one field amongst many fields of practical action that ethnomethodologists have studied. ${ }^{(6)}$ As Lynch and Bogen (1996) recommend for their study of courtroom practice, we have used an 'underbuilt methodology'.

In our project Laurier followed six different mobile workers (only one of whom we will report on here), all in the service sector, talking, taking fieldnotes, seeing as much of the action as he could and where possible recording it on video for reviewing later. What is purposefully absent from our present account is 'war stories' (Orr, 1996) of the mobile workers stuck between clients and headquarters, many instances of which Laurier overheard and, indeed, was told during his time spent with mobile workers 'in the field'. Such talk is an important component of the daily work and of regionbuilding (see Laurier and Philo, 1998), but in this paper we borrow a distinction made by Lynch (1985) in his studies of laboratory work. The divergence he pointed toward was between talk that speaks about the work and talk occurring as part and parcel of the work as it happens. Talk about the work is often part of having 'the tour' of the workplace as a visitor, and it leads to the more common description of work in the social sciences. It is akin to what you might get if you interviewed someone about his or her job, where he or she will offer comments of the kind that anticipate what a social researcher might like to know about identity, power relations, gender, and the like. Talk which occurs in the work and is the work is what we are more interested in here (such as, 'pass me the blue form', 'I can't give you figures because the system is down'). Talk about the work is not only offered to visiting social researchers, it is also used to introduce new employees to the job and is then entwined, assembled, and made sense of within a growing corpus of on-the-job instructions, tips, or war stories which lead to accomplishing the job. When Laurier first joined each driver, he would be told about certain aspects of the job, and these comments inform the description we are providing of 'Marge's' job, ${ }^{(7)}$ but our concern now is not to give readers 'the tour' but, rather, to use some detailed descriptions of parts of Marge's work to bring you into the situated nature of that work as an embodied and sequential course of conduct. This may mean that the text is hard to follow in places, as Marge's activities cannot be grasped immediately if they are to be learned and appreciated for what they do.

A problem that has beset ethnographers since the 'textual turn' is whether they can ever truly represent the voices and experiences of the people they research, and we are not about to ignore the fact that we, too, are using practices that render original phenomena into textual or pictorial formats to produce written documents which inevitably let slip details of what they purport to describe. The reason why nonrepresentational theory, actor-network theory, and ethnomethodology have argued against privileging texts and speech as representation, and getting caught in writing as endless textual play, is because when researchers write something they are not only doing 'representation'. They do their activities not only in the sense of political representation, nor as always referring to something. They are writing as a practical embodied activity just like any other practical embodied activity, and to say that it is all doing representing is to miss the detail of whatever we are engaged in, as when a person finds a parking warden writing them a parking ticket and sees her or him writing something that really does not 'represent' their Irish-American identity properly. The parking warden is not wrestling with a text to make a just and honest or critical 'representation', he or she is writing a parking ticket. We are not always writing about something;

(6) On administering questionnaires see Suchman and Jordan (1990), on the coding of a transcript see Garfinkel (1964), on ethnography see Sacks (1992) and Wieder (1974), on using video see Macbeth (1999) and Goode (1994).

(7) Names of individuals, companies, and cities are changed throughout for the sake of confidentiality. 
in fact, we are usually writing something specific with purposes and motives that are part and parcel of the writing.

Hence, the writing in this paper might be called an 'exhibit', in that we are trying to 'show' our argument. Along the way we will also make reference to video material, though it is of interest here only inasmuch as it makes available in unanticipated detail just how certain tasks were done. We will leave serious consideration of using video for another paper, and note only that its use as a technology for observing during fieldwork (and after) does not found any new discipline or provide objective data. Moreover, its analysis was not disengaged from it "being part of the work of producing, for colleagues, a practically adequate demonstration that something is the way the researcher says it is" (Livingston, 1985, page 63). Video does not only provide for observing, and the material it produces should not be mistaken for the embodied activities without which it could not be produced. Our use of video is in order to get technical access to the detail of practical embodied activities in situ; there are other ways, though none of them carries any special imperative in their access to social phenomena.

Our initial sweeping references to the processes used by a company to organise its regions will remain until we proceed to look at some of their specifics, "a gloss over a lively context whose ways, as a sense assembly procedure, we found no need to specify" (Garfinkel and Sacks, 1986, page 164). By avoiding specifying in advance exactly what is the region we risk appearing somewhat contrary in character. It is a risk worth taking, we believe, as the danger of offering precise definitions from the outset of a paper is that at best they catch readers' interests and at worst they lead to stipulative treatments of social practices. Our ambitions are to show by the end of this paper how a particular region is routinely constructed out of numerous car trips, the unpacking of boxes, and looking in car boots. Our attention is on practical actors, whose work "is never, not even 'in the end' available for saying in so many words" (page 164): it just is what it is that they are doing. Paraphrasing Garfinkel and Sacks still further, we do not mean that mobile workers do not know what they are doing; rather, they know what they are doing in the ways that they do it.

Talk is one of the ways in which they do it, yet talk is all too often attended to at the expense of what else is occurring. Some access can be gained to what they are doing, as we have suggested above, by asking them explicitly 'what are you doing?' and related elicitory questions. These questions will be tolerated by busy people doing their job, with the expectation that at some point you, the questioner, will work it out. Getting the point of what anyone is saying at the time is not resolved by transcription and coding of what is said, and yet it is routinely done. Deciding the correspondence between an informant's verbal formulations of their activities and the activities themselves cannot be achieved by merely quoting their talk about the work. Responses to questions offered as explanatory talk to visiting ethnographers "become a part of the selfsame occasion of interaction" and thereby "becomes another contingency of that interaction" (Garfinkel and Sacks, 1986, page 165). Moreover, whilst talk can extend and endlessly elaborate the activities which it is telling, it is also made sense of by members as part of the preceding, current, and consequent situation which it is contextualising, and it is open to further elaboration by members for further purposes. This active sense of talk as contextualising is a move similar to that of Thrift's nonrepresentational theory in reminding us that context "is not an impassive backdrop to situate human activity" (1996, page 3), and that the activity of contextualising is an indexical and open-ended one, settled only by and for practical purposes.

If we are to be genuinely surprised by what we hear and see in the field, then we must patiently listen to and look at the counting, measuring, evaluating, and decisionmaking as 
it actually occurs, rather than looking with a clever coding matrix already in hand for the 'interesting' bits of our fieldwork that seem to fit the code (Harper et al, 2000). Thrift thus flips over 'participant observation' to 'observant participation' to emphasise engagement rather than distance in theory, and for him nonrepresentational theory is about taking mundane matters seriously and thereby changing the avant-garde style of much work that passes as social and cultural geography. As Thrift puts it in his suggestions for what nonrepresentational theory might be:

"this is not a new theoretical edifice that is being constructed, but a means of valuing and working with everyday practical activities as they occur. It follows that this style of work is both anti-cognitivist and, by extension, anti-elitist since it is trying to counteract the still prevalent tendency to consider life from the point of view of individual agents who generate action by instead weaving a poetic of common practices and skills which produce people, selves and worlds" (Thrift, 2000, page 216).

Where we break stride with nonrepresentational theory and push off somewhere else is in not pursuing performance as an apt metaphor either to organise our investigations or to position it as any kind of contemporary structure of feeling. Our engagement with regional work did not lead us to prioritise its performative elements. It is an obvious point, yet we might as well reiterate it: we found a workplace whose orders of action, entitlements, and material arrangements did not carry over into other settings (such as opening a present at a romantic meal for two or feeding bears at the zoo). We did not find someone doing a performance of work or a performance at work. It seems to us that some of the dangers of overrating performance, just as much as overrating representation, is that we would miss just what it is that is going on in the here and now of a workplace. Or worse, without a commitment to some local practitioners doing the amazing yet ordinary and unnoticed work that they do, we would find ourselves sliding back into the realms of theatre, dance, and the elitist attitude of high culture from which we shifted a moment ago when we accepted that language is not primarily a means of representation.

\section{Marge at work}

\section{A lone employee in the company region}

In the following three exhibits we would like to direct readers' attention to the relative absence of coworkers from Marge's workplace. These single-worker scenes provide a striking contrast to studies by ethnographers of organisations, who are familiar with offices and with watching how teams of workers collaborate, share tasks, and mutually find and solve problems in centres of calculation or coordination (see also Brown, 2001; Harper et al, 2000; Luff et al, 2000; Suchman, 2000). In histories of traveling salesmen (Spears, 1995) and ethnographies of taxi driving (Davis, 1950; Psathas and Henslin, 1967), the lone-agent nature of such work has been highlighted and is not one that has entirely changed for Marge and her kind (even with the benefit of a mobile telephone). ${ }^{(8)}$ Marge is still relatively new to her job, and this prevalent feature of her mobile workplace was an issue for her. She spoke of how she missed the sociable environment of working in the open-plan office where she had previously been an accountant at a metal-casting factory. When Eric was finishing his fieldwork with her, she commented on how she would miss his company during the day, and her comments were echoed by all of the car-based workers that Eric accompanied.

Although it certainly should be noted that loneliness is one of the problems of traveling salespeople and mobile service-sector employees, we are not seeking to critique that feature of the job, as our commitment is to displaying the distinctive ways in which such a job, where someone works alone, has to be organised. We might

(8) See also the remarkable online history of taxi driving at http://www.taxi-l.org/cowboy.htm. 
note that there are other jobs which share this feature-those of lighthouse keepers, sports professionals, park wardens, security officers, homeworkers, taxi drivers, novelists, parking wardens, and teleworkers of various kinds. Occupational category does not determine lone working, as sometimes these jobs are done by a team of workers and equally there can be situations where an occupation that would normally involve working in a group only has one person working rather than a team. Even for Marge, there were sociable elements to her job: meeting up with her team in specific cafés and bars at certain times of day [the title of our project, "Meet you at junction 17", was based on this kind of meeting place off the motorway (Laurier and Philo, 1998)]. Mobile telephones have also become a key resource for shoptalk (see Laurier, 2001a; 2001b), playing their part in helping workers to maintain an ongoing awareness of the location of other members of their dispersed work team, what they are doing, where they are going next, and whether their paths might cross. To bond their workers further and build their team spirit in an otherwise dispersed work space, meanwhile, Marge's firm, the "Big Drinks Company" (BDC), organises a lot of nights out at clubs, promotional events, weekends away, and training weeks.

Marge's work, as defined by her employers, was as an 'area manager' with responsibilities for liaising with clients and promoting existing and new brands of drinks. However, her job title and its official description did not cover in any adequate way a description of what her day-to-day work involved.(9) To gain competence in the job she had to learn from carefully watching and listening to her coworkers, all of whom were constantly giving her tips, pointers, stories of good and bad ways of working, and embodied displays of the everyday conduct of this particular bunch of promotional and sales staff.

The largest part of Marge's time was spent traveling around by car and on foot in order to pay visits to a host of public houses, clubs, and other establishments which sell her company's range of drinks products. Intermittently, alongside her core venues, she also visited venues that did not use BDC distribution but might be persuaded to do so. For all of her clients, she outlined new products and new initiatives which were designed to attract customers (competitions, holidays, T-shirts, compact discs, and the like). Part of her role in the company, as she explained it to Eric, was to maintain the loyalty of establishments to BDC and its products, checking that the company was properly meeting BDC's expectations in terms of delivery, quality, and price. She did her best to extend the consumer base within current outlets, the range of BDC drinks ordered by such outlets, and also the numbers of outlets ordering from BDC. During her on-site encounters in pubs and bars, she went over their sales figures and promoted branded products to her clients. Her promotion involved some guidance for them in the uses and display of numerous promotional objects such as posters, miniatures, competitions with prizes, free-drinks offers, and so on. The promotional work was a collaborative task inasmuch as her clients knew very well, and sometimes better than Marge, how to promote various drinks to their customers. Much of her legitimacy in the bars was secured on describing the latest promotions from her company and, crucially, when passing over new and/or requested promotional objects to clients. The 'giveaway' of posters and T-shirts, as Brown (forthcoming) notes for the 'take away' of brochures and maps in tourist information centres, was key in the organisation of her interactions with her clients. In Brown's study, the setting is one where mobile clients come to visit a fixed service provider, whereas for Marge the reverse is true. In each case a considerable store of objects is kept that can be handed over, allowing for several things which we cannot detail but will mention briefly. Relevant features of

(9) Brown (2001) looks at the particular agreed-upon parts of a job that are recorded for the purposes of keeping an accurate and accountable time sheet. 
the objects can be brought to the receiver's attention by the giver; on the basis of seeing and handling the object, the receiver can ask questions immediately; and the objects can be annotated, adapted, or rejected as inappropriate to the receiver's plans. Finally, the 'give away' allows for the management of the timing of the encounter through either quickly handing over the objects or keeping them back.

Regions, as they were dealt with by Marge and her coworkers, were key spatial categories which provided for the allocation of tasks to employees, the distribution of goods, the monitoring of performance, the journeys, and the means of journeying of the workers. Regions were marked for Marge and her coworkers on maps, with clear spatial boundaries; they did not have clear temporal beginnings and ends, as, say, 'project' work has (see Lynch, 1985 on setting of a time span for projects). The spaces did change through time, with the TNC merging regions, or the TNC merging with other TNCs and adopting their regional arrangements. As a unit in the business of the team to which Marge belonged, a region might require temporary management by another member of a team if its manager was sick or left the company. As Lynch (1985) notes with the temporalisation of scientific practices in laboratory work, extensive courses of inquiry are produced as part of the social ordering of tasks in the immediate setting of the laboratory. Taking a geographical approach, we are noting that the organisation of the extensive nature of TNC's business is characterised by its regionalisation. For each and every manager of a region his or her daily job proceeds not only through what to do next (questions of serial ordering), but also through where to go next. A spatialisation of materials is here used in and as the formulation of these pressing matters.

\section{Packing for the car}

The 'dry store', which we will look at more closely below, was where Marge and her team kept all of their nonliquid materials, chiefly promotional items such as umbrellas sporting brand logos, posters and t-shirts, and cardboard cut-out figures used to advertise certain drinks lines. The BDC 'wet store', on the edge of the city, was a dedicated warehouse where all of the drinks products were stored, having been transported there from their points of production throughout the United Kingdom and across the globe. Marge was part of the service interface between the logistics of the high volumes of boxed BDC-branded drinks and the slower rhythms of a conversational, form-filling, and promotional-material handling encounter between her and each and every client.

To get a sense of just what a normally obscure yet essential part of the job involved, we will look at Marge's work in the dry store a little more closely (see box 1 on page 96). It is a simple point: Marge had to walk amongst the piled boxes to get at the items that she will pack into her car boot for 'today'. The boxes, in their sheer quantity and spatial arrangement as stacks with passages between, required Marge to walk the unappreciated distances of a snooker player around a snooker table. The boxes are, on the whole, unrecognisable at a glance and required Marge to read their labels up close, so she had to get close enough to various piles to read their labels and to select the appropriate box of stuff. Another simple point: they need opening. With all the ease that standardised boxes give logistics in terms of handling quantities of goods, at the end of the delivery chain there are unavoidable hours devoted to breaking them down into their usable units. The trolley gave shape to her gathering of the promotional material for 'today'. Alongside allowing her to move a large load of boxes, plastic-wrapped goods, cardboard cut-outs, and other paraphernalia, the trolley served as a useful proxy for her car interior (see boxes 2 and 3 on page 97).

As we noted earlier, Marge travels the interface between the uniformity of mass production and the bespoke tailoring of flavourings, T-shirts, posters, glasses, ice 
coolers, etc. She elaborates the spaces of her region with these objects as she unpacks brown boxes (repeating box 1 , lines $1-4$ ) when each time she has to find the right box and extract quantities of items to fit roughly the number of clients who she will see on this day. She keeps working away at unpacking the boxes and stacking the contents on the trolley until the trolley is full. Whilst order exists at all points, correspondingly, ordering needs to be done at all points by those available with what is available. For Marge, working for BDC, her company does not provide a purpose-built structured space that she can use, although it does provide an endless supply of boxes. She and her coworkers use the orderliness of the local buildings, the history of the box stacks, the order of where they have to go today, what they have at hand, and still other cues as well, to continue unrelentingly to produce more organisation that they and others can recognise.

Stacking boxes has sequenced aspects in terms of what gets packed on top of what, or below what, or in front of or behind what. What is 'first put down' tends to be 'last picked up', as new boxes get piled on top of old. Such a process can accumulate trouble for the accessors of stacked boxes if the products inside have expiry dates. In Kawatoko's (1999) seafood-warehouse study, the boxes that needed moving urgently as their contents approached their expiry date tended to be at the bottom of stacks. The problem was resolved in the seafood warehouse by the stackers using front and back spread, and left and right spread, whilst the accessors extracted boxes from the stack in reverse (see Kawatoko, 1999 for more details). In the BDC dry store, matters are less pressing, as the stock will not go off and most of it is of low per-item financial value. Because of the constant cycles of product promotion much of it becomes junk fairly fast and so needs to be disposed of when products change or promotions end. In fact the pressure for its disposal comes more from the push of the constant arrival of more boxes of material than from the pull of client demand. Nevertheless, stacking the boxes, like retrieving the boxes from Marge's car boot, was implicated in the organisation of what objects go to where, and when. The piles were used to prepare Marge (or whoever else might be doing her job) for moving or opening any of these boxes.

To switch away from Marge for a moment longer, Kawatoko (1999) discusses how, in the high-speed and highly staffed space of the seafood warehouse, the loads of frozen seafood brought into the warehouse are spatially arranged by the warehouse workers according to information provided by written labels on 'packages' and 'tags' which tell them whether the fish is for sale in local markets or for factory processing. These labels also reveal relevant aspects of intended customers, the likely timings of deliveries to different customers, the types of fish, and their varying 'seasonableness' relative to where it is destined, and so on. As Kawatoko (1999, page 237) deduces, "The workers use both the arrangement of goods and the tags and marks indicating the kind of food to make inferences about what is going to happen", and the "resource workers' - the more senior warehouse workers-complete complex calculations, written and then left on display to those who need to know on a blackboard, to ensure that the loads are spatially assembled in the most efficient manner (packing the space most fully but leaving loads easily accessible in the right order). Spatial replacements and temporal sequences here dovetail, and Kawatoko proposes that this example demonstrates how:

“... diverse spatial resources are not contained within fixed boundaries but require 'occasional' arranging. ... The workers' use of space in the refrigerated warehouse demonstrates that the arrangement of space is [an] ongoing and occasioned accomplishment with various resources, and simultaneously that arranged space becomes part of the resources for making projected actions visible" (page 330).

Moreover, Kawatoko refers to the spatial disposition of loads in the warehouse as a 'representation', a spatial announcement of what the different loads represent in terms 
of both their at-a-glance indication of big, medium, and small quantities of different fish products and, more unusually, the future of 'projected actions' to be conducted on and with these loads, notably as they are removed from the warehouse to be distributed to different sites for processing or marketing ('exchange'). This displacement of the term 'representation' to such mundane spaces is germane to our study of Marge's regional organisation. It echoes Lynch's (1994) "exploded view" of representation, "examining what people do when they engage in an activity that makes one or another 'representation' perspicuous" (page 149). In both our case and in Kawatoko's case, the ongoing piling of boxes to form shapes and dispositions provides an embodied record of past actions and a shaping-up of future actions. We therefore follow Kawatoko's move in deconstructing 'representation' as a monological concept. In mentioning representation, we are not implying a picture that refers to an inaccessible reality, or a sign corresponding to a meaning or an interior cognitive mental map that forms an inner picture of the outer world of the warehouse. We are simply raising the possibility of regarding this mundane, box-busy, spatially and temporally elaborated workplace as endlessly formulating 'representations' in the flow and direction of reception, storage, and delivery labour linked to the arranging of the warehouse, yet we would not wish to say that the seafood factory is 'doing representation'.

Marge was no novice in piling her boxes in relation to and as part of her work for the day nor was she starting from scratch each day. She knew through looking at the piles, and doing her travels from venue to venue how the organising of her boxes in her bay was implicated in the organising of her region. Indeed, although she worked alone in the store more often than not, she did so with her coworkers in mind, as we see in box 1 (frames and lines 5-9) when she borrowed some boxes from her boss. The store was an asynchronously shared workplace presenting an interesting set of coordination problems managed through the placement of artefacts in space. Like tying a knot in a hanky, some boxes were left open - flaps akimbo-or brought to the front to serve as reminders that these items should be noticed. Sometimes people did this as reminders to themselves and at other times as reminders to their coworkers for whenever they were handling the boxes. The placement of boxes or their status as open or closed provided additional spatial announcements akin to those mentioned by Kawatoko (1999).

Marge was concerned, like most of us, to avoid hassle if at all possible, and so she did her packing and subsequent unpacking with an economy appropriate to the excess of promotional material that was constantly flooding the store. Her packing and unpacking were economical in the sense that we could imagine much more formal and elaborate ways of matching items to venues, involving detailed relabeling on arrival, maps, labeled shelving, colour-coded boxes, and the like. Instead, Marge did what she could in the time that she had available to do it by stacking items into more permanent piles by types of item and size of box. She and her coworkers also exhibited and found their work visible as spatially organised work by using the zones in the store: arrivals, the four bays, and the trolley for taking things to the car. In other words, a lot could be inferred about a plain brown box merely by where it was currently placed, where it had been placed before, and whether it was open or closed.

In her walking back and forth with the cardboard boxes, Marge can be seen as 'thinking' space (see Latour, 1986) or, as Ryle might put it, she was using the space intelligently (see also Kirsh, 1995; Latour, 1986). Without rushing, falling, dropping, breaking her materials, she made an orderly spatial arrangement of the boxes, the promotional materials, from which she concurrently and subsequently selected items for giving to clients. It was also a practically reasoned matter of piling objects by their qualities as fragile, robust, flat, round and square, and their impending destinations. In box 1 (frame and line 9), Marge shows Eric her dirty hands: aside from the joke that she 


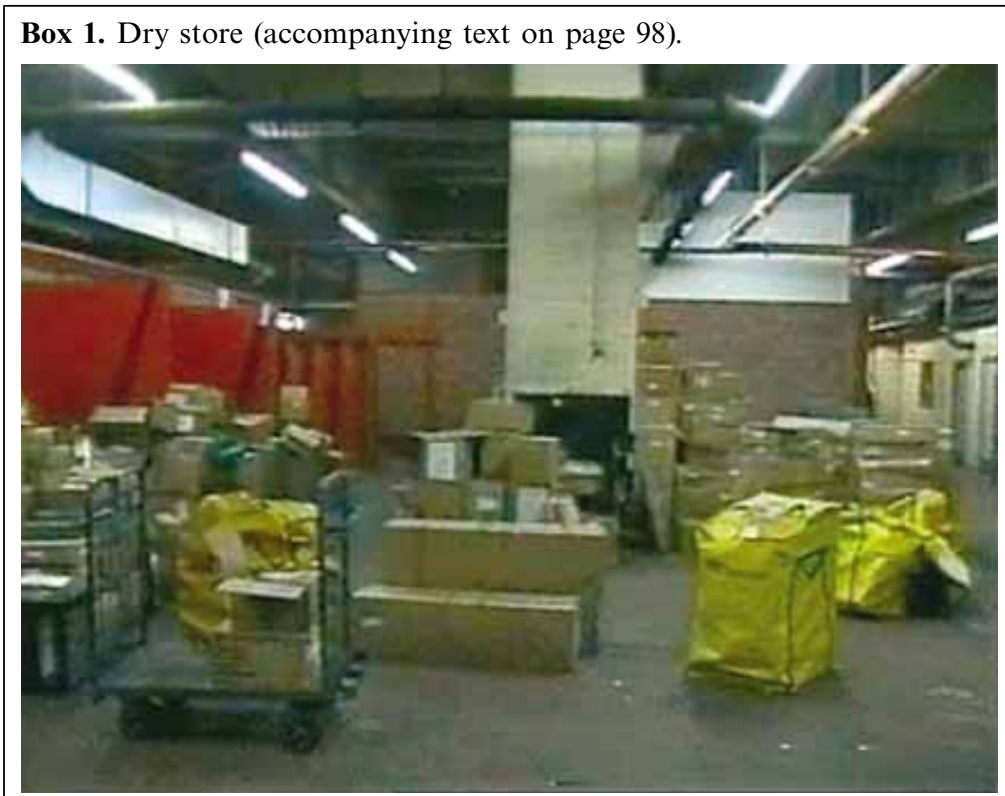

This activity takes a good twenty minutes. Before Marge enters the dry store she has checked over the list of items that she needs for 'today'. The unpacking takes place in a large underground room (see above) crowded with boxes, entailing four purpose-built storage bays and one improvised one. There are also a few filing cabinets.

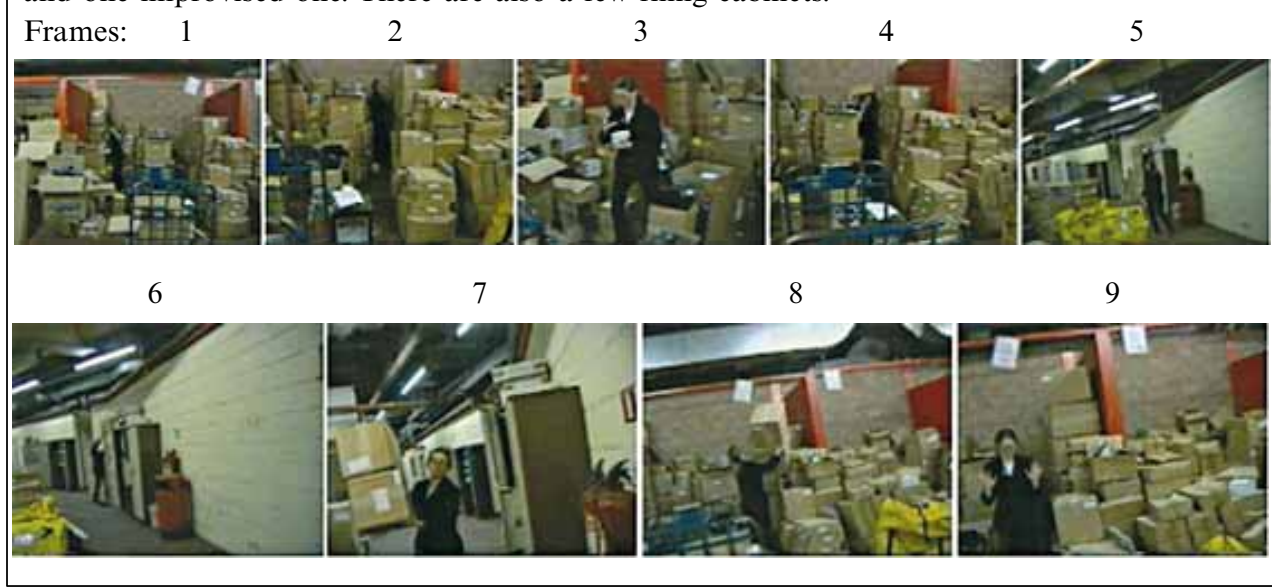

is making, she is also showing where work is. In describing the 'ways of the hand' on a piano keyboard required to make jazz, Sudnow makes an observation applicable to Marge's less glamorous but equally embodied making of her region. Sudnow's looking at his hands traveling across the keyboard, like Marge's hands on her boxes, "is party to a kind of imaginary conceiving of various aspects of the territory in which I was moving" (1978, page x). ${ }^{(10)}$ Moreover, our description of the dry store provides an interesting alternative to computer-supported cooperative work studies of workplaces joined in the same temporal frame by computer technologies, where virtual environments

(10) Sudnow's phenomenological investigation of jazz-piano playing is particularly pertinent as he is concerned, as part of his making music through the play of his fingers on the keyboard, with "finding the way". Indeed, he compares it to finding the way from one house to another via various means (1978, page 148). 
Box 2. Looking speculatively in the boot (accompanying text on page 98).

In a car park full of pot holes, with a CCTV camera surveying it from above and the blank backs of several buildings surrounding it, Marge is at work. We have called in at one of the bars she visits infrequently. It is in a fairly poor neighbourhood, has a low turnover of her branded spirit drink, and buys a lot of its drink from other cheaper distributors. Marge says all of this as part of explaining to me why she gives it the attention that she does.

Frames: 1

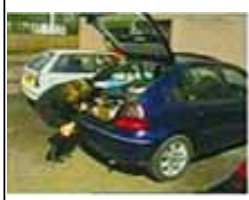

6

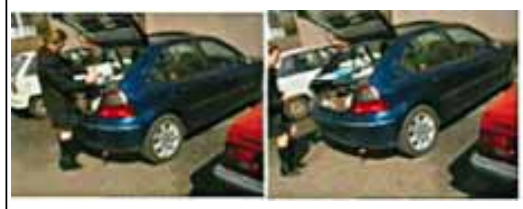

2

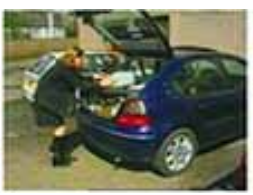

7

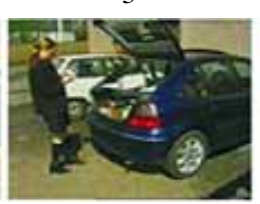

8

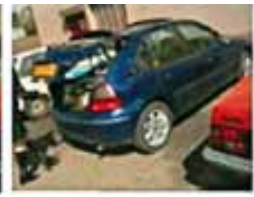

4

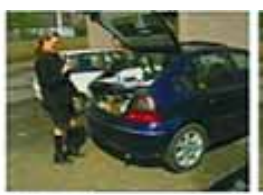

9

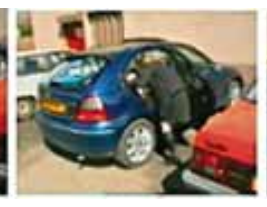

5

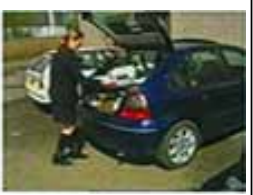

10

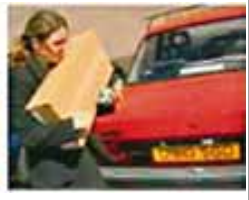

Box 3. Looking confidently in the boot (accompanying text on page 99).

Parked just off a busy street in the city centre, Marge is about to make one of her regular visits to a style bar which is part of a club.

Frames: 1

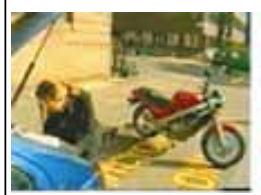

6

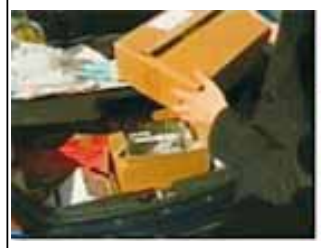

2

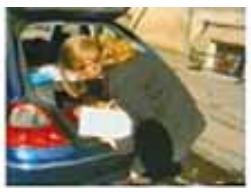

7
3

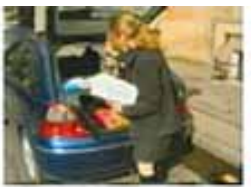

4

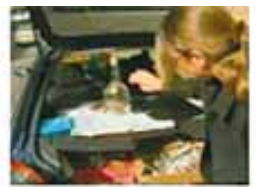

8
5

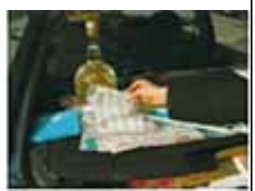

9
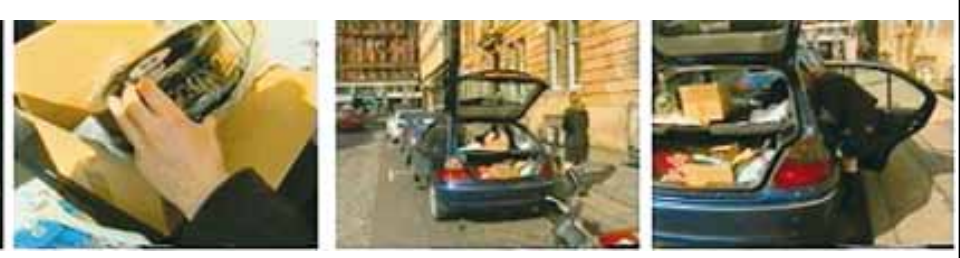

are used to articulate work tasks (Hindmarsh et al, 2001). In our study we have a shared 'real' space where the workers make asynchronous visits and manage tasks through the spatial arrangement of artefacts (see also Brown, forthcoming). The placement of boxes, plastic packs, and so on is usually accompanied by talk either during coffee meetings or over their mobile telephones: "I left the flavourings for Blue Bar out for you".

\section{Delivering things}

In all of the hours that Eric spent sitting in the passenger seat with mobile workers like Marge, he almost never witnessed them using a conventional map. Occasionally they used an 'A to Z' when they had time to park to check an address and work out a route to get there. Much more common was their voicing of route directions (Psathas and Henslin, 1967; see also Psathas, 1991; Schegloff, 1972) either to themselves or when checking over the mobile telephone with other mobile workers, nonmobile employees 
Box 1. Dry store.

Lines:

(1) Marge checks the labels on a wall of boxes in an adjoining bay (that is, not her assigned one).

(2) She opens a large box, and pulls out a handful of postcards.

(3) Marge walks across the room. She transfers them to an open box on her trolley, walks back,

and looks at the labels on the boxes.

(4) She opens another box. She pulls out some glasses from a box in her bay, walks with them over to the trolley, and walks back.

Whilst I am asking her a question about which boxes belong to who, it reminds her that she has swapped some items with her boss and is to take with her some of her boss's promotion material.

(5) Marge walks over to her boss's improvised bay.

(6) She picks two boxes from the top of a high pile, which requires her to stretch up for them.

(7) She walks with the boxes (they are clearly lightweight, if big).

(8) She adds the boxes to her bay.

(9) Marge walks back showing me the palms of her hand as a joke about how dirty the job is.

(10) She picks up another box, and carries it over to her bay.

Box 2. Looking speculatively in the boot.

Lines:

(1) Marge opens the boot, and bends forwards so that her line of sight is directly into the boot.

(2) Looks in and pulls out a white cardboard box of glass tumblers (unopened). She places the white box out of the way on the parcel shelf, and pushes down the protruding lid of a large brown cardboard box so that she can reach right to the back of the boot.

(3) Pulls out an eight-pack of miniature bottles sealed in transparent plastic shrink-wrap. As she stands upright, she holds the eight-pack slightly away from her body. As she does this she says:

Marge: (staring at eight-pack) "Oh excellent, I've got some."

Eric: (from behind camcorder) "What's that, is it flavouring?"

Marge bends down again and reaches toward the same dark nook in which she found the eight-pack.

(4) She pulls out a single miniature, turns her head slightly in the direction of Eric and the camera, waggles the pack, then puts it down on parcel shelf.

Marge: "Yeah, it's flavours."

Eric: "So they do flavoured vodkas."

(5) Marge places the single bottle onto the parcel shelf, "Yup". Continues to search in boot for a few seconds.

(6) As she explains to Eric about the history of vodka flavourings in Russia she tears open the shrink-wrap. From the eight-packs she takes two bottles, and puts them with the single one.

The remaining bottles in flared plastic wrap of box (now open) are put to the back of the parcel shelf.

(7) Marge looks in the back of the boot. Repacks, and the medium-sized unopened white box is packed first. Leaves the opened pack of concentrates to the front.

(8) Marge closes the boot.

Marge: "... and it's all fruit flavours like plum and apple and cranberry and blackcurrant".

She opens the rear door of the car.

(9) Pulls out a box of T-shirts with a logo (unopened).

(10) She closes the door and then walks away with the box in her arms, bottles in her fingers, to the bar. 
Box 3. Looking confidently in the boot.

Lines

(1) Marge opens the boot.

(2) Pulls out the white box of tumblers (unopened) from left.

(3) Lifts out bottle of new branded spirit line.

(4) Places it on parcel shelf.

(5) From the right of the boot, in a large brown cardboard box (opened), pulls out small shot glasses wrapped in loose transparent plastic (unopened). Places the shots glasses in a heap beside the spirit bottle.

(6) Marge pulls out a medium-sized brown box containing a base for rotating and illuminating the bottle of new branded spirit.

(7) Places it on the parcel shelf, opens it, and checks the contents.

(8) Leaves the car in order to feed the parking meter.

(9) Returns to the car, opens the back door, and picks up contact sheets to check if the club had requested any other items.

Marge: "Fine"

Closes the door. Picks up the box, bottle, and glasses from parcel shelf. Closes the boot. Walks away from the car towards the bar.

at head office, or even clients being visited. As Marge drove across her region, she used her acquired local geography of the roads. The geographical knowledge that Marge was calling upon was, once again, not a 'mental map'; it was, rather, the occasioned use of what she knew from driving these roads many, many times and at this moment being on this road, at this junction, waiting to taking this exit, or this third turn on the left. Her step-by-step consulting of a visible road system gave her only a handful of ways ahead, ways that were bound to the course that she took. Marge's 'map' of the region's roads - if indeed we can all it this, and we have our doubts - was therefore less an abstract concept in her head, ${ }^{(11)}$ and more a series of embodied engagements with hands and feet, upon wheels, buttons, and levers in response to her looking ahead at the roads she traversed. Her car, in the controls that it offered and on the paths that it can take, gave her a 'flatland'-like simplified route as an ongoing sequence of prompts to practical actions (Lynch, 1993).

Thinking further about Marge's use of her car to deliver things, we would argue that distinctive to being a car-based worker was her ability to use the car as much more than just something for getting from A to B. The car also had to be part of the local arrangement of a large organisation - a link in the chain of its production, as Latour (1992; 1999) so often remarks - and it had to function as actor and as network. In combination with more directly related driving tools that her vehicle possessed to move around the city, Marge's car had to double as an operational work space, full of the different sorts of equipment and documents rendering it a 'mobile office' as well as a delivery vehicle. To serve these purposes her car became a tightly packed storage space, full of diverse kinds of objects. In its sequential position between the warehouse and the bars and clubs, the interior space of her car was thoroughly bound up in the organisation of her region.

From the trolley (see box 1) at the warehouse loading bay, Marge divided her items into the front seat, back seat, and boot of the car, always with storage and swift retrieval in mind. The front-seat area, aside from being her driving position, was most closely tied to her office activities of telephoning, checking over documents, and

(11) We follow Ryle (1949) and Wittgenstein (1953), among others such as Coulter (1983), Latour (1999), and Garfinkel (1991), in rejecting — via an ordinary language critique — a Cartesian version of mind. In our view, Marge does not carry around a 'mental' minimap inside her head which a 'mental' mini-Marge consults behind her eyes. 
typing up on her laptop whilst sitting. The back seat had a mix of additional less-relevant documents, clothing, and usually some of the more fragile promotional items (such as polystyrene and plastic cutouts), that could be accessed, albeit not without considerable bodily contortion from the front seat. The boot was only accessible when the car was stationary and Marge could get out to do certain tasks there. This fact had certain implications for the arrangements of her tasks, as obviously Marge could not check the contents of the boot while in transit. Although a great deal could be said about Marge's use of the front and back seats, we are going to concentrate now on the work that she does at the car boot during two contrasting client calls. We have selected the work around the boot as it is an almost unnoticed (by researchers) zone of the car, and it is the place where the objects from the BDC store go to next before finally arriving at their destination in a pub or bar (see box 2).

In the talk that occurs during Marge's rooting around in the boot, we can find the distinction between talk that is in the work and talk about, in this case, 'the product'. In the short history and listing of flavourings, which we have left largely untranscribed, Marge instructed Eric in some parts of the 'lore' of the product, mentioning its origins in Russia and so on (Cook et al, 1998). Before Eric elicited this response, Marge was visibly busy and involved in rooting around in her car boot. Even as she tolerantly ran through some on-the-spot 'interviewing' about flavourings, she remained engaged in trying to do what she was doing before she was interrupted. Her back was turned to Eric; she kept pulling boxes in and out, searching in the interior of the car, and her talk did not inform, shape, or otherwise than very loosely formulate what she was doing in the car. Marge's first words, "Oh excellent I've got some", are nonetheless characteristic of talk as part of the work. Not only was the 'some' pronoun only sensible through reference to the shrink-wrapped eight-pack of miniature bottles that she held in her hands, as Eric's "what's that?" query shows, but it was also only sensible to those who do Marge's job. Without video material to check back to, the audio transcript would be frustratingly indecipherable, leading an analyst to ask 'some of what?'. And without the analyst having an employee's competence in BDC products, what she found 'some of' would remain fairly incomprehensible.

Her declaration on finding the eight-pack was not secondary to the silent work that she was doing as she rooted around in the boot. It was located in the timing of her activities: it arrived as the eight-pack was displayed, and it formulated what she had been doing as an uncertain search. "There they are" at the same point would have been heard as saying that she came to the car feeling certain that the flavourings were there. Yet, her formulation provided something else: there are some objects that Marge is well aware she has in the car and others that might or might not be there. To find out about these objects that might not be there she has to consult the boot, in much the same way that we might hunt around in our kitchen cupboards to find out if we have a particular ingredient for a recipe. Marge did not search the whole boot, she proceeded quickly, knowing that if the flavourings were there then they would be at the back. By comparison with kitchen cupboards again, Marge has put certain objects into certain zones within the boot and could thereby locate them without turning the whole boot over. Her searching was implicated in the spatialisation of the objects as the older and unused boxes get pushed to the back by the arrival of new and immediately relevant boxes. In the latter part of the description in box 2, as Marge replaced items from the parcel shelf back into the boot, we saw this process in action. The most recently used box of now-opened concentrates was packed toward the outside. By its replacement it was made immediately available to Marge on the next occasion when she opened the boot. Her awareness of which objects are in the boot has been assembled in the acts of packing and repacking. The flavourings, for example-as a result of this occasioned search of 
the boot-have switched from possibly in the boot to definitely in the boot. Should Marge's next client not request flavourings, nor the next after that, the objects which are pulled out for use and then repacked will gradually push the flavourings to the back of the boot again. From what is going on in the boot we can then build toward how it is that when Marge is talking with a client, on being asked for some item, she would say: "I have them with today, I'll go get you some", or, "Hmm, I'm not sure, let me go check".

What is beginning to come out is the kind of organising that goes on each and every time Marge went to the boot. We are showing some of the ways that the work at the boot is predominantly silent work with objects. When Marge said things aloud, it assisted the ethnographer by highlighting a significant moment in what she was doing when she would otherwise stay silent. It further formulated her activities to someone who could not be expected to share her perspective on her task fully. Just what Marge might be talking about she makes clear by her posture, by her brief pause to take what was an extended look at the bottle, which thereby emphasised that this was an object of her concern. By way of comparison, the white box went straight from the boot to the parcel shelf without Marge stepping back and taking that kind of look at it.

In her discovery that there were definitely some miniatures in the boot, and in their subsequent placement to the front of the boot space, we see her doing a little bit of spatial arranging that would leave things in a prospective order for the rest of the day. In other words the daily accumulating repackings of objects in the boot fed consequentially into the preceding and subsequent business interactions of her day.

In box 3 Marge was at work and beside her car again. It was later on in the day from the previous visit to a bar. She characterised this visit as a 'drop-in', and had told Eric that she dropped in to this bar several times in a week and sometimes more than once a day. She knew these clients well, and they were important clients. Not only did they have a high turnover of BDC's products, they also had a close relationship to the marketing of current and new products. As Marge put it, they had a more fashionconscious clientele who are willing to try new products and are a test bed for launching new products. If products do not sell in these venues then they may be delayed for a while and remarketed.

Marge did not have to pull boxes out of the way this time when she was accessing the boot as all the items that she needed were in the top layer, where they could be picked up quickly. They were spread out across the top of the stuff in the boot from left to right, making a spatial announcement of just which items were to be delivered to this venue. The danger, for instance, of leaving an item for this delivery in the back seat would be that it would be forgotten by Marge and left behind. In this practical way Marge visualised for herself all of the promotional parts of the product that needed delivering here today. One of Marge's dilemmas as a lone worker was that reminding cannot easily be shared out to anyone else on her team. She had to remind herself constantly through the use of these spatial announcements about which items were needed in which places as she traveled. Packing played an integral part in providing such prompts or announcements from which she could make inferences later in the day when unpacking and repacking. The success of her reminders consisted not only in the 'things to do' she could remember standing alone, but was secured in the representation that she regularly assembled in the variety of items packed and repacked as the deliveries and spares today.

If we now return to Marge, to unpack swiftly and confidently the right things for the right place required careful preparation earlier in the day. Her objects were not in her boot simply to be seen as a variety of objects, for each one was an accountable artefact. They are accountable in the sense that we could ask Marge why each object was there, and she would be able to provide an account such as "Blue Bar asked me for six packs of branded tumblers", or as earlier when she explained to Eric about the 
bottles of flavourings, or the occasion shown in box 3 when she explained that she was delivering the display equipment for the new product.

What the parcel shelf offered was a sequentially related spatial zone (see Evergeti, 2000; Hindmarsh and Heath, 2000) in which to get the glasses, bottle, and base ready by placing them upon it in clear view (box 3, frames 7-9). A parcel shelf allows car users the possibility of leaving items there while they are doing something else, as in Marge's case when she had to feed the parking meter. Although the items are still 'on hold' on the parcel shelf, she returned to her contact sheet for this client to double check whether there was anything that she still had missed. She announced "Fine" aloud: once again it might have been said silently to herself, or not at all, were Eric not standing by with a camcorder. Whatever, it marked the end of the task of gathering stuff from the boot. This time her gathering of items from the boot was different: it was less speculative, more confident. She had packed items earlier in the day, to be taken out now, on the basis of preexisting requests from the style bar. To get the task done for this time required unpacking - the shots glasses being moved from the boot to the shelf, as was the bottle of spirits. The base unit was quickly inspected to see if it had all its parts. Unpacking for this place was untroubled and relatively routine compared with the previous venue. She displayed the work as such in her busy involvement with it, only briefly saying "Fine" as a gloss over the untroubled progress of her work in the boot. Even though it is routine, the clever counter-top promotional display for the product does not pop-up at the style bar whole; rather, it arrives in small boxes and plastic wrappers, which will need further assembly in situ by the bar staff.

What emerges in this second description of Marge getting items out of the boot of the car is that each finding of materials, and each repacking afterwards, has its spatial and temporal existence as 'this time' and 'this place'. Even though 'finding the flavourings' and 'unpacking the display' are seemingly good examples of what she was doing, they were also unique efforts to find what she needed there and then, which were consequentially related to the organisation completed earlier, as well as making some provision for what she would do later.

\section{Surely the work could be a little more exciting?}

"Now I adopt what is in a way a counter-strategy to the issue of 'interesting' and that is that I'm specifically picking utterly uninteresting data. Things which do not have for us any special lay interest. That means that in order to find its interestingness we have to find that whatever it is that's interesting about it is what we can say about it. And we can then develop criteria of interestingness where we're not exploiting kinds of things we 'want to know about' - scandalous topics, gossip etc. Things like an exchange of greetings are kind of ideal rather than, say, the discourse of kings or salon conversations, where we know in the case of the latter that it's important and interesting, and it's very hard in the first instance to ignore 'what they say', which you have to do."

Sacks (1992, page 293)

Part of our tactic when looking in detail at the activities that happen with really rather dull anonymous cardboard boxes was to wait to see what it would give us of interest, rather than, as Sacks notes, exploiting a kind of thing that might be taken to be interesting already, like 'big decisions' at headquarters. ${ }^{12)}$ The sales performance is

(12) As Bowker and Star warn of pursuing the uninteresting: "There are many barriers to this exploration. Not least among them is the barrier of boredom. Delving into someone else's infrastructure has about the entertainment value of the yellow pages of the phone book. One does not encounter the dramatic stories of battle and victory, of mystery and discovery that make for a good read" (1999, page 322). This apt warning comes from their book on the histories and current 
another one of those more spectacular occasions in the making of a company region, and in no way do we wish to deny its importance, yet we would suggest that it has also perhaps hidden from researchers other constitutional elements of service-sector work. $^{(13)}$ Somewhat counterintuitively for cultural geographers, we have pushed ourselves away from events that resembled performances. With further restraint we have made ourselves look away from the maps on the walls of headquarters in order to observe where and with what else the company space is being organised. Hopefully there is some surprise in the fact that we found cardboard boxes playing a key role in the spatial organisation of a company region.

In this paper we have sought to bring into focus the unnoticed work of mobilising diverse objects through activities that are spatially reflexive: in that just as the objects are used in practically ordering the space so it is that the space is used to order the objects for all practical purposes. As Thrift (1996; 1999) urges, in his nonrepresentational theory of time-space, we have dwelt on the objects involved in region-making. We have shown how they form an equipmental complex for both managing a region and doing promotional work. Although we have been wary of suggesting that these kinds of objects have a life of their own, we have shown how they become useful in a particular form of life. Moreover, we have brought out their agency in the joint field of action where a human subject is clearly not a naked agent (our particular subject was in danger of being lost among the abundance of materials that her job involved). As it turned out, our mobile worker was visiting the sites in her region in order not just to have the richness of face-to-face contact, but to hand over the particular parts of the company product for which she was responsible. In terms of their topology, the places that she and her work materials moved between connected up in a horizontal sequential order, where the workplace of the warehouse fed into the workplace of the car parked beside the venue, which then fed into both face-to-face meeting and future occasions of 'boot work'. Marge's spread-out workplace did not provide her with a permanent and stable overview; each task proceeded in a step-by-step arrangement shaping up the possibilities for what could happen next. In explicating these matters, we have tried to study the organisation of a region in concretia as an ordinary matter of transportation and its technologies.

The selective extracts from our research, in boxes $1-3$, hopefully offer the reader some grasp of the minutely ordered actions required for the management and servicing of a region. These local methods were indefinitely more diverse, rich, and complex than those summarised in handbooks given to the TNC's regional managers or during their training sessions or throughout other written guides to management. The labour of service was never simply the enactment of scripts, or technical instructions, or the advice of bosses, or other members of the team. It relied on numerous commonsense competences with the materials at hand, such as selecting items to carry for each 'today', stacking boxes, checking items against lists, and so on:

"... how do we pack the world into words? ... I want to show that there is neither correspondence, nor gaps, nor even two distinct ontological domains, but an entirely different phenomenon: circulating reference" (Latour, 1999, page 24).

Our work also might add something to Latour's (1999) excellent study of a botanist, pedologist, and geographer at work gathering data in the field where the earth of the (12) (continued)

workings of official classification schemes. Their study has strong affinities with ours, not only in its choice of fairly dry subject matter, but also as it spells out some elements of the endless work done everywhere locally by whoever is available, and responsible, to index and to elaborate upon the seemingly abstract and objective classifications of standardised codes (see also Brown, 2001, on 'time sheets').

(13) Indeed, part of our research has emphasised aspects of this face-to-face work, as well as showing how a kind of 'face work' also occurs over the telephone (see also Laurier, 2001a). 
Boa Vista is to be mapped and analysed. He studied the scientists' practical activities of progressive selection of quadrats for gathering samples, sampling, labeling, transportation, boxing, counting, and eventual writing-up as a research report. Whereas Latour was revealing both how science is grounded in practical activities and how those activities are arranged in chains of tasks with particular methods and apparatuses, we are following a shorter section of a chain traveling in the opposite direction from centre of calculation to regional space, to reveal how business, rather than science, is grounded in practical activities (see also Boden, 1994). For Latour, what was important was how referencing was stretched out, how it was stabilised even as it was transformed, for the practical purposes of making accountably objective 'samples' small enough and light enough to ship them from South America to Europe. We might say that he too, like Lynch, was exploding out scientific representation into myriad actual activities with objects: labeling a branch, filling out a logbook, filing photographs in a cabinet, comparing soil to a Munsell code chart. In comparison, we have looked at the far end of a commercial chain from the companies' centres of calculation, and here on the dispersed work floor of the company region we have documented the unpacking of boxes: the work of matching particular places to mass-produced promotional items. Our concerns have been to investigate how a region is tied to this circulation of products as a practical embodied activity with boxes, hands, car boots, and more.

As a final reflection, it occurs to us that 'unpacking' is often used metaphorically by ourselves for the objects of our discipline: dense terms or arguments that require explication, as in unpacking ideological baggage. In considering some actual unpacking as an ordinary method, we have noted how it is the laying out of objects in space that formulates the space in terms of its current state while also shaping up future actions. Unpacking, then, offers a way of displaying and collecting things for current and later use. In unpacking we find what we have from a collection wherein we did not necessarily know with certainty all that we had, and we also discover what has been left behind. We may shape-up what we have for where it has to go next in our handling and laying out of the objects, with an eye to where we intend finally to put them (Büscher, 2001). An unpacker's work is in resolving if something, in a collection of items, that might be there, is really there. It can be approached with or without a list, with or without an intended findable item (there are items that could not be found through unpacking). In tracing how the packing relates to the work that we have to do, we can look confidently or speculatively into just what our vehicles contain. Taking our text as a vehicle, we have packed it fairly tightly and now hand the burden of unpacking it over to you.

Acknowledgements. Thanks to referee A for five pages of really inspiring and challenging comments on and criticisms of this paper, it is as much yours now as it is ours (sorry!). We gratefully acknowledge the receipt of ESRC funding (ESRC Award reference number R000222071) for "Meet you at junction 17: a socio-technical and spatial study of the mobile office"; Marge and our other mobile workers for their tolerance, good humour, and willingness to put up with a passenger-seat ethnographer; and Erin Sheehan and Pete Merriman for organising the session on transport at the New York AAAG 2001, where a first version of this paper was presented; the staff at Glasgow University's Media Services and Mike Shand must also be thanked for their assistance with video and image processing, and Barry Brown for allowing us to borrow the quote which he borrowed from Julian Orr about 'work'. Final thanks to Lucy Hawkes for her careful editing.

\section{References}

Allen J, Massey D, Cochrane A, 1998 Rethinking the Region (Routledge, London)

Boden D, 1994 The Business of Talk (Polity Press, Cambridge)

Bowker G, Start S L, 1999 Sorting Things Out, Classification and its Consequences (MIT Press, Cambridge, MA)

Brown B A T (forthcoming), "Tourist centres", http://www.dcs.ac.uk/

Brown B A T, 2001, "Unpacking a timesheet: formalisation and representation" Computer Supported Cooperative Work 10293 - 315 
Brown B A T, Green N, Harper R, 2001 Wireless World (Sage, London)

Büscher M, 2001 Ideas in the Making PhD thesis, Department of Sociology, University of Lancaster, Lancaster

Cook I, Crang P, Thorpe M, 1998, "Biographies and geographies: consumer understandings of the origins of foods" British Journal of Food number 199, 162 - 167

Coulter J, 1983 Rethinking Cognitive Theory (Macmillan, London)

Crang P, 2000, "Organisational geographies: surveillance, display and the spaces of power in business organisation", in Entanglements of Power: Geographies of Domination/Resistance Eds J Sharpe, P Routledge, C Philo, R Paddison (Routledge, London) pp 204-218

Davis F, 1950, "The cabdriver and his fare: facets of a fleeting relationship" American Journal of Sociology $45158-165$

Dix A, Beale R (Eds), 1996 Remote Cooperation: CSCW Issues for Mobile and Teleworkers (Springer, London)

Du Gay P, 1996 Consumption and Identity at Work (Sage, London)

Evergeti V, 2000, "Paper mail and the social organisation of space", conference proceedings from the "Social Constructions of Space"; available from TomkeLask, Laboratoire D'Anthropologies de la Communication, University of Liège, Liège

Foucault M, 1987 The Dark Labyrinth (Athlone, London)

Garfinkel H, 1964, "Studies in the routine grounds of everyday activities" Social Problems 11 $225-250$

Garfinkel H, 1991, "Respecification: evidence for locally produced naturally accountable phenomena of order, logic, reason, meaning, method etc. in and as of the essential haecceity of immortal ordinary society (I) - an announcement of studies", in Ethnomethodology in the Human Sciences Ed. G Button (Cambridge University Press, Cambridge) pp $10-19$

Garfinkel H, Sacks H, 1986, "On formal structures of practical actions", in Ethnomethodological Studies of Work Ed. H Garfinkel (Routledge and Kegan Paul, London) pp 160 - 193

Goffman E, 1969 Where the Action Is (Allen Lane, London)

Goode D, 1994 A World Without Words: The Social Construction of Children Born Deaf and Blind (Temple University Press, Philadelphia, PA)

Goodwin P, Cairns S, Dargay J, Parkhurst G, Polak J, Stokes G, Vythoulkas P, 1995 Car Dependence RAC Foundation for Motoring and the Environment and the Economic and Social Research Council Transport Studies Unit, University College London, Gower Street, London WC1E 6BT

Harper R, 2001 The Organisation in Ethnography: A Discussion of Ethnographic Fieldwork Digital World Research Centre, University of Surrey, Guilford

Harper R, Randall D, Rouncefield M, 2000 Organizational Change in Retail Finance: An Ethnographic Perspective (Routledge, London)

Heath C, Hindmarsh J, Luff P, 1999, "Interaction in isolation: the dislocated world of the London Underground train traveller" Sociology 33 555-576

Hindmarsh J, Heath C, 2000, "Sharing the tools of the trade: the interactional constitution of workplace objects" Journal of Contemporary Ethnography 29523 - 562

Hindmarsh J, Fraser M, Heath C, Benford S, 2001, "Virtually missing the point: configuring CVEs for object-focused interaction", in Collaborative Virtual Environments Eds E Churchill, D Snowdon, A Munro (Springer, London) pp 115 - 139

Kawatoko Y, 1999, "Space, time and documents in a refrigerated warehouse" Human Studies 22 $315-337$

Kirsh D, 1995, "The intelligent use of space" Artificial Intelligence 7331 - 38

Latour B, 1986, "Visualization and cognition: thinking with eyes and hands" Knowledge and Society $61-40$

Latour B, 1992, "Where are the missing masses? The sociology of a few mundane artefacts", in Shaping Technology/Building Society Eds W E Bijker, J Law (MIT Press, Cambridge, MA) pp $225-258$

Latour B, 1999 Pandora's Hope, Essays on the Reality of Science Studies (Harvard University Press, Cambridge, MA)

Laurier E, 2001a, "Why people say where they are during mobile phone calls" Environment and Planning D: Society and Space $19485-504$

Laurier E, 2001b, "The region as a socio-technical accomplishment of mobile workers", in Wireless World Eds N Green, B Brown, R Harper (Springer, London) pp 46-60

Laurier E, 2001c, "Notes on dividing the attention of a car driver" TeamEthno-Online issue 1, paper 1, http://www.teamethno-online.org/ 
Laurier E, Philo C, 1998 Meet You at Junction 17: A Socio-technical and Spatial Study of the Mobile Office Economic and Social Research Council, Polaris House, North Star Avenue, Swindon SN2 1UJ

Laurier E, Philo C, 1999, "X-morphising: review essay of Bruno Latour's Aramis or the Love of Technology" Environment and Planning A 31 1047-1071

Laurier E, Maze R, Lundin J, 2002, "Putting the dog back in the park: animal and human mind-in-action", http://www.geog.gla.ac.uk/ elaurier/texts/dogwalk3.pdf

Law J, Hetherington K, 1999, "Materialities, spatialities, globalities", http://www.comp.lancs.ac.uk/sociology/soc029jl.html

Livingstone E, 1985 Making Sense of Ethnomethodology (Routledge, London)

Luff P, Hindmarsh J, Heath C, 2000, "Introduction", in Workplace Studies: Recovering Work Practice and Informing System Design Eds P Luff, J Hindmarsh, C Heath (Cambridge University Press, Cambridge) pp $1-28$

Lynch M, 1985 Art and Artifact in Laboratory Science: A Study of Shop Work and Shop Talk in a Research Laboratory (Routledge, London)

Lynch M, 1993 Scientific Practice and Ordinary Action: Ethnomethodology and Social Studies of Science (Cambridge University Press, Cambridge)

Lynch M, 1994, "Representation is overrated: some critical remarks about the use of the concept of representation in science studies" Configurations 2(1) $137-149$

Lynch M, Bogen D, 1996 The Spectacle of History, Speech, Text and Memory at the Iran - Contra Hearings (Duke University Press, Durham, NC)

Macbeth D, 1999, "Glances, trances, and their relevance for a visual sociology", in Media Studies: Ethnomethodological Approaches Ed. P L Jalbert (University Press of America, Lanham, MD) pp $135-170$

Orr J E, 1996 Talking About Machines: An Ethnography of a Modern Job (Cornell University Press, Ithaca, NY)

Philo C, Parr H, 2000, "Institutional geographies: an introduction" Geoforum $31513-521$

Philo C, Wilbert C, 2000, "Animal spaces, beastly places: an introduction", in Animal Spaces, Beastly Places: New Geographies of Human - Animal Relations Eds C Philo, C Wilbert (Routledge, London) pp $1-28$

Polanyi M, 1958 Personal Knowledge (Routledge and Kegan Paul, London)

Psathas G, 1991, "Direction-giving in interaction", in Talk and Social Structure Eds D Boden, D H Zimmerman (Polity Press, Cambridge)

Psathas G, Henslin J M, 1967, "Dispatched orders and the cab driver: a study of locating activities" Social Problems $14424-443$

Ryle G, 1949 The Concept of Mind (Hutchinson, London)

Sacks H, 1992 Lectures on Conversation, Volumes 1 and 2 (Blackwell, Cambridge)

Schegloff E A, 1972, "Notes on a conversational practice: formulating place", in Studies in Social Interaction Ed. D Sudlow (Free Press, New York) pp 75-119

Spears T B, 1995100 Years on the Road: The Traveling Salesman in American Culture (Yale University Press, New Haven, CT)

Suchman L, 2000, "Making a case: 'knowledge' and 'routine' work on document production", in Workplace Studies: Recovering Work Practice and Informing System Design Eds P Luff, J Hindmarsh, C Heath (Cambridge University Press, Cambridge) pp 29-45

Suchman L, Jordan B, 1990, "Interactional troubles in face-to-face survey interviews" Journal of the American Statistical Association 85232 -241

Sudnow D, 1978 Ways of the Hand: The Organization of Improvished Conduct (MIT Press, Cambridge, MA)

Thrift N, 1994, "Taking aim at the heart of the region", in Human Geography: Society, Space and Social Science Eds D Gregory, R Martin, G Smith (Macmillan, London) pp 200-231

Thrift N, 1996 Spatial Formations (Sage, London)

Thrift N, 1999, "Steps to an ecology of place", in Human Geography Today Eds D Massey, J Allen, P Sarre (Polity Press, Oxford) pp 295-322

Thrift N, 2000, "Afterwords" Environment and Planning D: Society and Space 18 213-255

Wieder D, 1974 Language and Social Reality: The Case of Telling the Convict Code (Mouton, The Hague)

Wittgenstein L, 1953 Philosophical Investigations translated by G E N Anscombe (Basil Blackwell, Oxford) 